\title{
Escolas Criativas: experiências transformadoras potencializadas na interação do Ensino Superior com a Educação Básica
}

\author{
Marlene Zwierewicz * \\ João Fabricio Guimara Somariva ** \\ Marcia Bianco *** \\ Miryan Debiasi ${ }^{* * * *}$ \\ Rosilane Damazio Cachoeira ${ }^{* * * * *}$ \\ Maria Canever da Silva $* * * * * *$ \\ Liene Silveira ${ }^{* * * * * * *}$ \\ Marilei Morgan Veronezi Bratti $* * * * * * * *$ \\ Maria Marlene Schlickmann $* * * * * * * * *$ \\ Dorly Spíndola Luareth Zanelato ${ }^{* * * * * * * * * *}$ \\ Brígida Marioti $* * * * * * * * * * *$ \\ Regis Quadros da Silva
}

\section{Resumo}

A interação entre o Ensino Superior e a Educação Básica é uma das condições valorizadas nos processos de avaliação dos cursos de graduação, especialmente nas licenciaturas, estimulando que as instituições universitárias ampliem a articulação entre o ensino, a pesquisa

\footnotetext{
Professora do Centro Universitário Barriga Verde - Unibave (Santa Catarina/Brasil). E-mail: marlenezwie@unibave.net

** Professor do Centro Universitário Barriga Verde - Unibave. E-mail: joao.unibave@gmail.com

${ }_{* * *}$ Professora do Centro Universitário Barriga Verde - Unibave. E-mail: marcia.bianco@yahoo.com.br

**** Professora do Centro Universitário Barriga Verde - Unibave. E-mail: miryan@unibave.net

***** Professora da Escola Barriga Verde - EBV - Centro Universitário Barriga Verde - Unibave. E-mail: educacaobasica@unibave.net

****** Professora da Secretaria de Educação de Balneário Rincão/SC. E-mail: mariacanever@gmail.com

$* * * * * * *$ Professora da Secretaria de Educação de Balneário Rincão/SC.

******* Professora da Secretaria de Educação e Cultura de Grão Pará/SC. E-mail: marileiveronez@yahoo. com.br

******** Professora da Secretaria Municipal de Educação, Cultura e Esportes de São Ludgero/SC. E-mail: maria.marlene0809@hotmail.com

********* Professora da Secretaria de Educação, Inovação, Cultura, Esporte e Lazer de Gravatal/SC. E-mail: dorly@gravatal.sc.gov.br

********** Professora da Secretaria de Educação, Cultura e Desporto de Urussanga/SC.

*********** Professor da Secretaria de Educação, Cultura e Desporto de Urussanga/SC. E-mail: brigidamarioti@hotmail.com
} 
e a extensão. Considerando a importância desse processo, este artigo tem como objetivo contextualizar o papel desempenhado pelas Escolas Criativas na interação entre o Centro Universitário Barriga Verde - Unibave e redes municipais de ensino do sul de Santa Catarina (Brasil), destacando, nesse processo, escolas de referência no desenvolvimento de um ensino transdisciplinar e ecoformador. Para a realização do estudo, optou-se pela pesquisa documental e pelas abordagens qualitativa e quantitativa, condições que propiciaram a análise de projetos de extensão do Unibave e de Projetos Criativos Ecoformadores - PCE, elaborados por gestores e docentes a partir do desenvolvimento do Programa de Formação -Ação em Escolas Criativas, ofertado às secretarias municipais de educação, por meio de uma parceria entre o Unibave e as Redes Internacionais de Escolas Criativas - RIEC e RIEC Brasil. Os resultados indicam a ampliação do número de redes municipais que se vinculam ao programa e do número de PCE elaborados anualmente, consolidando um processo de aproximação do planejamento a perspectivas mais transdisciplinares e ecoformadoras, bem como a relevância de escolas que têm se transformado em referência por sua capacidade de transcender, recriar, valorizar e transformar.

Palavras-chave: Escolas Criativas, Ensino Superior, Educação Básica, Transdisciplinaridade, Ecoformação.

Creative Schools: transformative experiences enhanced by the interaction between higher education and the basic education

\begin{abstract}
The interaction between Higher Education and Basic Education is one of the conditions considered in the process of evaluation of undergraduate courses, especially teaching courses, stimulating that the university institutions extend the links between teaching, research and extension. Considering the importance of this process, this article aims to contextualize the role of Creative Schools in the interaction between the Barriga Verde University Center - Unibave and municipal school systems of southern Santa Catarina (Brazil), noting, in this process, reference schools in developing transdisciplinarity and ecoformative teaching. For the study, we opted for documentary research and qualitative and quantitative approaches, which allow the analysis of extension projects of Unibave and Ecoformative Creative Projects - PCE, prepared by managers and teachers based on the development of the Training-Action Program in Creative Schools, offered to municipal departments of education, through a partnership between the Unibave and the international Networks of Creative Schools - RIEC and RIEC Brazil. The results indicate the expansion of the number of municipal school systems that affiliate themselves with the program and the number of PCE produced annually, consolidating a process of using more transdisciplinary and ecoformative perspectives in planning, as well as the relevance of schools that have become a reference for their ability to transcend, recreate, value and transform.

Keywords: Creative Schools, Higher Education, Basic Education, Transdisciplinarity, Ecoformation.
\end{abstract}




\section{Introdução}

Indícios de criatividade podem ser situados em diferentes escolas, independentemente de suas concepções pedagógicas. Em consonância com essas concepções, contudo, cada escola tende a priorizar um conceito de criatividade e, em decorrência disso, dinamiza um processo pedagógico que pode se situar em determinado ponto de uma escala.

No primeiro extremo da escala há o Paradigma Positivista (MORAES, 2004), que incide em práticas centradas em competição, exclusão e fragmentação, estimulando uma criatividade limitada ao desenvolvimento de estratégias didáticas vinculadas à reprodução linear de conhecimentos historicamente acumulados. No segundo extremo está o Paradigma Ecossistêmico, que, para Moraes, é “[...] construído a partir de intercâmbios nutridores entre o sujeito e o objeto, mediante diálogos, interações, transformações e enriquecimentos mútuos [...]" (2004, p. 42-43), por isso prioriza a solidariedade, a inclusão e um ensino contextualizado.

O referencial de Escolas Criativas, foco deste estudo, converge com o Paradigma Ecossistêmico. Nesse sentido, incorpora o conceito de Torre que as define como instituições:

[...] que vão mais adiante do lugar do qual partem (transcendem), que dão mais do que têm e ultrapassam o que delas se espera (recriam), que reconhecem o melhor de seus estudantes e professores (valorizam), que crescem por dentro e por fora, buscando em tudo a qualidade e a melhora (transformam) (2013, p. 13).

Tendo como objetivo contextualizar a proposta das Escolas Criativas - referenciadas por Torre $(2009,2013)$ - na interação entre a Educação Superior do Centro Universitário Barriga Verde - Unibave, situado em Orleans (Santa Catarina - Brasil), e as redes municipais de ensino do sul catarinense, destacando, nesse processo, escolas de referência no desenvolvimento da proposta -, este estudo pautou-se pela pesquisa documental e pelas abordagens qualitativa e quantitativa. Na coleta dos dados, foram analisados projetos de extensão do Unibave e Projetos Criativos Ecoformadores - PCE, elaborados por gestores e docentes de redes municipais de ensino que têm participado do Programa de Formação-Ação em Escolas Criativas, desenvolvido por meio de uma parceria entre o Unibave e as Redes Internacionais de Escolas Criativas - RIEC e RIEC Brasil. 
Além de vincular as Escolas Criativas às perspectivas de um ensino transdisciplinar e ecoformador, aspectos que permeiam o Paradigma Ecossistêmico, o estudo apresenta a dinâmica do Programa de Formação-Ação em Escolas Criativas e transformações detectadas no planejamento dos docentes, bem como instituições de referência em transdisciplinaridade e ecoformação.

As Escolas Criativas e as premissas do pensamento complexo e de um ensino transdisciplinar e ecoformador

Uma educação vinculada às demandas atuais e atenta às incertezas em relação ao futuro traz a responsabilidade de superar paradigmas centrados na competição, na exclusão e na fragmentação. González Velasco (2015) destaca que esse processo implica a discussão dos conceitos de 'complexidade' e 'transdisciplinaridade', enquanto Torre e Zwierewicz (2009) acrescentam o conceito 'ecoformação', formando uma tríade que permeia a proposta das Escolas Criativas.

Priorizando os três conceitos, este estudo apresenta o Paradigma Ecossistêmico como determinante na elaboração e dinamização das Escolas Criativas, uma proposta originada nas discussões do Grupo de Pesquisa e Assessoramento Didático - GIAD da Universidade de Barcelona, nos primeiros anos do século XXI. A partir de 2008, com a interação do então coordenador do GIAD, Saturnino de la Torre, com pesquisadores e docentes brasileiros, a proposta das Escolas Criativas foi fortalecida, criando-se uma metodologia que a transladou do mundo das ideias e a dinamizou a partir da realidade das instituições de ensino brasileiras (ZWIEREWICZ, 2013).

O Paradigma Ecossistêmico é um dos quatro paradigmas destacados por Moraes (2004) e situa-se no extremo de uma escala onde se posicionam formas significativamente diferenciadas de conceber a educação. A Figura 1 representa a escala de posicionamento dos paradigmas e caracteriza a distância entre o paradigma que norteia as Escolas Criativas em relação ao Paradigma Positivista, cuja ênfase disciplinar reforça a competição entre os estudantes, a exclusão dos que não se adaptam ao processo de reprodução e a fragmentação dos conhecimentos, distanciando-os da realidade. 
Figura 1 - Paradigmas Educacionais

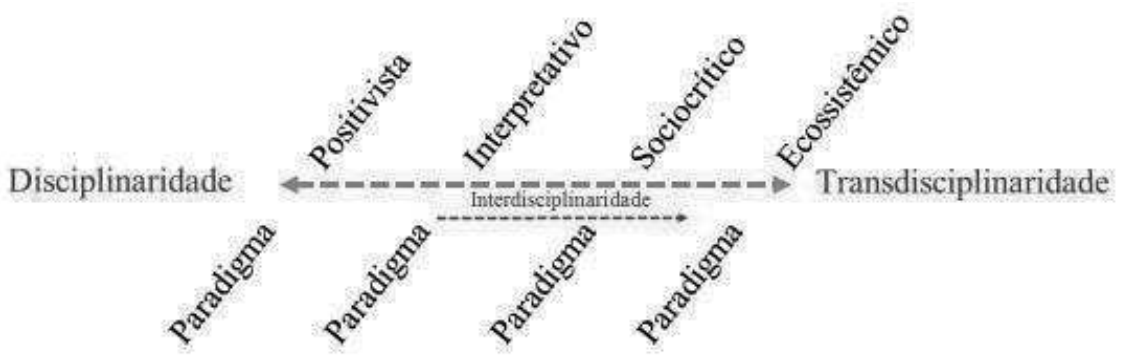

Fonte: Elaborado a partir dos paradigmas contextualizados por Moraes (2004)

Ao privilegiar o pensamento reducionista, Morin lembra que o Paradigma Positivista não apreende a "[...] multidimensionalidade das realidades [...]" (2004, p. 112). Ao refletir sobre as consequências dessa perspectiva no contexto escolar, vale lembrar o alerta do autor sobre uma inadequação cada vez mais “[...] ampla, profunda e grave entre os saberes separados, fragmentados, compartimentados entre disciplinas, e, por outro lado, realidades ou problemas [...] transversais, multidimensionais e transnacionais, globais, planetários." (MORIN, 2009, p. 13).

A persistência desse paradigma educacional na educação brasileira interfere na organização curricular, nas metodologias e nos processos avaliativos adotados em sala de aula. "[...] Por se constituir em um paradigma educacional secular, as possibilidades de superação tardam a se efetivar, resultando em práticas excludentes e que privilegiam os estudantes que têm mais facilidade de memorizar." (ZWIEREWICZ, 2015, p. 13).

Apesar da relevância dos dois paradigmas intermediários para os avanços atuais da educação, este estudo tem como foco as diferenças educacionais advindas das duas concepções posicionadas nos extremos da Figura 1. Faz-se pertinente dizer que há uma diversidade de nomenclaturas utilizadas pelos pesquisadores para indicar os dois paradigmas. Enquanto Moraes (2004), por exemplo, intitula-os como Paradigma Positivista e Paradigma Ecossistêmico ou Emergente, Flach e Behrens (2008) usam as nomenclaturas Paradigma Newtoniano-Cartesiano e Paradigma da Complexidade.

Tendo em vista que o paradigma no qual a escola se apoia define sua maneira de pensar e transparece em suas ações (MORAES, 2004), as Escolas Criativas priorizam perspectivas de superação da cegueira do conhecimento, mencionada por Morin (2001), estimulando uma preocupação com o bem-estar das pessoas, da sociedade e 
da natureza (TORRE; ZWIEREWICZ, 2009). É a partir dessa perspectiva que o Paradigma Ecossistêmico se vincula ao pensamento complexo, já que parte do pressuposto de que "[...] não há separatividade, inércia ou passividade [...]", pois "Tudo está relacionado, conectado e em renovação contínua.” (MORAES, 1996, p. 61).

Tendo sua origem vinculada ao avanço do conhecimento e aos desafios do século XXI advindos do processo de globalização (SANTOS, 2009), o pensamento complexo foi sistematizado pelo próprio Morin, reconhecido atualmente como o pensador planetário na área da educação (ZWIEREWICZ, 2015).

A complexidade, especificamente, é considerada "[...] efetivamente uma rede de eventos, ações, interações, retroações, determinações que sustentam nosso mundo fenomenológico [...]." (MORIN; CIURANA; MOTTA, 2009, p. 44). O que é complexo "[...] recupera, por um lado, o mundo empírico, a incerteza, a incapacidade de se atingir a certeza, de formular uma lei eterna, de conceder uma ordem absoluta. Por outro, recupera alguma coisa que diz respeito à lógica, ou seja, à incapacidade de evitar contradições" (MORIN; CIURANA; MOTTA, 2009, p. 44). Os autores também lembram que, etimologicamente, o termo complexidade procede do latim, derivando da palavra "[...] complectere, cuja raiz plectere significa trançar, entrelaçar. Remete a trabalho de construção de cestas que consiste em entrelaçar o círculo, unindo o princípio com o final de pequenos ramos." (MORIN; CIURANA; MOTTA, 2009, p. 43).

O pensamento complexo contribui para a inserção no currículo escolar de "[...] questões relacionadas ao meio ambiente, aos valores humanos, à solidariedade e tantos outros aspectos esquecidos pela escola desconectada da vida [...]" (ZWIEREWICZ, 2014, p. 9). Diante disso, vale lembrar que colabora também para consolidar uma prática pedagógica que supera a ênfase de processos que "[...] ensinam a isolar os objetos (de seu meio ambiente), a separar as disciplinas (em vez de reconhecer suas correlações), a dissociar os problemas, em ver de reunir e integrar." (MORIN, 2009, p. 15). Zwierewicz (2015) registra que, apesar de a possibilidade parecer utópica quando comparada à realidade atual de grande parte das instituições de ensino, é necessário reforçar a posição de Morin quando ele defende que "[...] o conhecimento científico não pode tratar sozinho dos problemas epistemológicos, filosóficos e éticos [...]" (2007, p. 21) presentes na realidade atual e, possivelmente, na futura.

Os conceitos que se vinculam ao pensamento complexo contrapõem-se aos princípios cartesianos de fragmentação do conhecimento e dicotomia das dualidades, propondo, em seu lugar, outra forma de pensar os problemas contemporâneos (SANTOS, 2009), o que colabora para a superação do pensamento reducionista, que, para Morin, não apreende a "[...] multidimensionalidade das realidades [...]" (2004, p. 112). 
Entre os referencias que facilitam a vinculação do pensamento complexo ao currículo escolar situam-se a transdisciplinaridade e a ecoformação, brevemente contextualizados a seguir.

Transdisciplinaridade: constitui-se, com frequência, em esquemas cognitivos que podem atravessar as disciplinas (MORIN, 2009), rompendo, portanto, com as barreiras disciplinares. Seu conceito caracteriza essa função, pois nele está implícito o prefixo 'trans' que “[...] diz respeito ao que está entre as disciplinas, através das diferentes disciplinas e além de toda disciplina. Sua finalidade é a compreensão do mundo atual e, para tanto, um dos seus imperativos é a unidade do conhecimento." (NICOLESCU, 2014, p. 50-51).

Zwierewicz (2014) registra que, apesar de ter se destacado recentemente, a transdisciplinaridade não é uma visão tão nova como aparenta, tendo em vista que para Morin“[...] o desenvolvimento da ciência ocidental, desde o século XVII, não foi somente um desenvolvimento disciplinar, mas também um desenvolvimento transdisciplinar [...]" (2001, p. 135). O conceito passa a ter sentido na área educacional, contudo, quando Piaget exterioriza que a diversidade envolvendo a realidade transparece "[...] tensões criativas para novas ideias e novas práticas que atravessem o conhecimento simplificador" (1970 apud NASCIMENTO, 2007, p. 210-211). Apesar disso, a educação formal tem costumeiramente optado pelo uso fragmentado dos conhecimentos, isolando as ciências, como se não fosse possível e necessário o diálogo entre elas, além de não considerar o que elas mesmas não têm incluído como objetos de estudo (ZWIEREWICZ, 2013).

A priorização da transdisciplinaridade, unida à interdisciplinaridade, não tem por pretensão subestimar a importância da disciplinaridade, tampouco da multidisciplinaridade e da pluridisciplinaridade. Coincidimos, portanto, com as reflexões de Nicolescu quando o autor afirma que “[...] seria muito perigoso considerar essa distinção como absoluta, pois a transdisciplinaridade seria esvaziada de todo o seu conteúdo e a eficácia de sua ação seria reduzida a nada" (1997, p. 6).

Contudo, a ênfase é justificada porque a transdisciplinaridade é concebida como uma postura, um espírito integralizador diante do saber, uma vocação articuladora para a compreensão da realidade, sem abandonar o respeito e o rigor pelas áreas do conhecimento (NICOLESCU, 2005). Também pode ser definida como a busca do sentido da vida por meio de relações entre os diversos saberes (ciências exatas, humanas e artes) numa democracia cognitiva (SANTOS, 2009).

Sua incorporação no ensino contribui para criar metodologias educacionais que estimulem uma compreensão mais global do mundo, considerando, nesse proces- 
so, o universo interior do ser humano, o universo exterior e a interação que existe entre esses dois universos (NICOLESCU, 2005). Nesse processo, a transdisciplinaridade não subestima a importância da disciplinaridade, contudo diverge em sua finalidade, pois a compreensão do mundo atual não pode ser inscrita na pesquisa disciplinar (NICOLESCU, 1997).

Ecoformação: pode ser compreendida “[...] como a formação recebida e construída na origem das relações diretas com o ambiente material: os não humanos, os elementos, a matéria, as coisas, a paisagem" (SILVA, 2008, p. 101). A autora também menciona que o termo passou a circular na década de 1990, sob a influência do Grupo de Pesquisa em Ecoformação e Educação para o Ambiente da Universidade de Montréal/Québec, articulando-o às reflexões sobre a aplicabilidade dos pressupostos do Pensamento Complexo no campo da Educação Socioambiental. Esse grupo de pesquisa era coordenado, na época, por Gaston Pineau.

Silva destaca também que a ecoformação fortalece as relações recíprocas pessoa-ambiente, sendo que "[...] o objeto da educação relativa ao ambiente não é o ambiente enquanto tal, mas a relação do homem com ele.” (2008, p. 101). Sua intenção é contribuir para “[...] estabelecer as premissas teóricas das unidades ecológicas de base que religam o homem à natureza [...]" (2008, p. 101), enfatizando “[...] a relação com o ambiente natural como processo essencial de consolidação da condição humana [...]” (2008, p. 101).

\begin{abstract}
A ecoformação está relacionada às demandas da realidade atual, quando se vive uma emergência planetária, com enormes problemas relacionados entre si. Entre esses problemas está a contaminação e degradação dos ecossistemas, o esgotamento de recursos naturais, o crescimento incontrolado da população mundial, os conflitos bélicos atrozes e incompreensíveis em nosso grau de civilização, a perda da diversidade biológica, linguística e cultural, "Tudo isso acrescentado a uma profunda crise econômica global que não parece ser uma crise de crescimento, mas sim uma mudança de sistema" (MALLART, 2009, p. 29).
\end{abstract}

Zwierewicz destaca que sua "[...] aplicabilidade no campo das instituições educacionais colabora para a efetivação de práticas transdisciplinares, possibilitando articular conhecimentos historicamente acumulados aos outros tipos de conhecimento." (2015, p. 36). Além disso, a autora lembra que a perspectiva “[...] colabora para transformações no contexto, fortalecendo a resiliência dos implicados que se posicionam diante das necessidades e as reconfiguram, buscando mobilizar o entorno." (2015, p. 36). 
A metodologia dos Projetos Criativos Ecoformadores - PCE na dinamização da proposta das Escolas Criativas

A metodologia dos projetos tem suas “[...] raízes no movimento da Escola Nova, também chamada de Escola Ativa, a qual surgiu no fim do século XIX e início do século $\mathrm{XX}$, dentro de um contexto de mudanças que se processava na vida moderna." (MENEZES; CRUZ, 2007, p. 3). Para esses autores, as ideias de Dewey e de seus seguidores trouxeram contribuições importantes para a educação do nosso tempo, destacando a preocupação da relação entre educação e realidade social, a aproximação das experiências do estudante com as atividades do meio em que vive e com seus interesses, as ideias de interdisciplinaridade, a cooperação como um princípio permanente do trabalho pedagógico. Nesse sentido, considera-se que, ao desempenhar um papel determinante na configuração da Escola Nova, o Paradigma Interpretativo constituiu-se com uma base preliminar para transformações que se processam na realidade educacional atual.

A partir da metodologia de origem foram sendo criadas outras possibilidades, propondo uma formação mais humanizadora e não somente vinculada às necessidades do mundo do trabalho. Na década de 1960, por exemplo, a ideia dos projetos compôs a pedagogia libertadora de Paulo Freire, quando surgiram os temas geradores, contribuindo significativamente ao debate sociopolítico nos processos escolares (ZWIEREWICZ, 2014). Já no contexto internacional, especificamente na Europa, Menezes e Cruz (2007) destacam o trabalho de Josette Jollibert, realizado na França, por meio de propostas pedagógicas inovadoras, como a Pedagogia de Projeto, bem como o trabalho de Fernando Hernandez, que desenvolveu os Projetos de Trabalho. Esta proposta influenciou significativamente a metodologia usada em escolas brasileiras, especialmente no final do século XX e início do século XXI (ZWIEREWICZ, 2014).

Já no ano de 2009, na obra Uma escola para o século XXI: Escolas Criativas e resiliência na educação, foi lançada a metodologia dos Projetos Criativos Ecoformadores - PCE, uma proposta determinante na dinamização das Escolas Criativas no sul catarinense. Torre e Zwierewicz (2009), pesquisadores responsáveis por sua criação, afirmam que sua diferença não está na capacidade de estimular criatividade, diálogo, colaboração e geração de novos conhecimentos, porque outros tipos de projetos já fazem isso, mas, sim, em sua competência em trabalhar no ensino a partir da vida, voltando-se para esta com soluções projetadas no contexto de aplicação, por meio da implicação de situações e recursos que vão além da simples reprodução do conhecimento científico. Para esses autores, os Projetos Criativos Ecoformadores - PCE podem ser assim caracterizados: 


\begin{abstract}
- representam um referencial de ensino e aprendizagem baseado em autonomia, transformação, colaboração e busca do desenvolvimento integral; - partem dos interesses dos estudantes e de sua realidade, transcendendo o conhecimento científico, por meio do desenvolvimento de atitudes colaborativas, solidárias e conectadas com a vida;

- estimulam uma prática educativa flexível e aberta às emergências que precedem sua aplicação e às que surgem durante seu desenvolvimento;

- fomentam a resiliência dos estudantes e dos próprios docentes, que ressignificam seu pensamento enquanto ajudam a ressignificar o entorno.
\end{abstract}

Com uma estrutura formada por dez organizadores conceituais, a proposta apoia pensamentos que mobilizam docentes e estudantes a transitarem entre conteúdos curriculares e a realidade, transformando-a a partir dos trabalhos realizados no decorrer do ano letivo. Nesse sentido, ela estimula a pontecialização de escolas que transcendem, recriam, valorizam e transformam, incorporando, portanto, o ensino transdisciplinar e ecoformador valorizado pelas Escolas Criativas.

\title{
Percursos metodológicos
}

A inclinação deste estudo pela pesquisa documental justifica-se por sua eficiência em oferecer informações na coleta de dados de diferentes fontes (MARCONI; LAKATOS, 2006), entre as quais estão os documentos produzidos por gestores educacionais e por docentes vinculados à Educação Básica e ao Ensino Superior. Além da análise de projetos de extensão ligados ao Programa de Formação-Ação em Escolas Criativas, desenvolvido por meio da parceria entre Unibave, RIEC e RIEC Brasil, a pesquisa documental favoreceu a análise dos PCE elaborados por gestores e docentes que atuam em cinco Secretarias Municipais de Educação do sul catarinense (Balneário Rincão, Gravatal, Grão Pará, São Ludgero e Urussanga), condição que facilita a identificação de escolas que potencializam sua capacidade de transcender, recriar, valorizar e transformar.

Quanto às abordagens, optou-se pela qualitativa, facilitando o tratamento de dados cuja pretensão não se limitava a "[...] numerar ou medir unidades ou categorias homogêneas." (RICHARDSON, 1999, p. 79), bem como pela quantitativa, por possibilitar a escolha do que pretendia ser aferido "[...] e apenas conservar o que é mensurável de modo preciso [...]” (LAVILLE; DIONNE, 1999, p. 43). Enquanto a abordagem qualitativa favoreceu a análise de documentos, a quantitativa assegurou avaliar a capilarização do Programa de Formação-Ação em Escolas Criativas, mensurada pelo número 
de municípios que têm participado do Programa de Formação-Ação em Escolas Criativas e pela quantidade de PCE elaborados na Educação Básica.

\section{Resultados e discussão}

Considerando o objetivo deste estudo, são apresentados a seguir os resultados da análise documental que possibilitou contextualizar o Programa de Formação-Ação em Escolas Criativas e sua implicação no planejamento de gestores e docentes das redes municipais que se vinculam à proposta. Além de sistematizar o programa a partir dos registros compilados nos projetos de extensão, indica-se o número dos municípios participantes e dos Projetos Criativos Ecoformadores - PCE desenvolvidos, bem como as escolas que despontam como referência a partir do desenvolvimento do programa.

\section{- O Programa de Formação-Ação em Escolas Criativas na interação entre Unibave e a Educação Básica}

Os projetos de extensão do Unibave registram que o Programa de Formação-Ação em Escolas Criativas foi criado na instituição no ano de 2013, com a finalidade de apoiar a rede pública de ensino do sul catarinense, por meio de iniciativas pedagógicas inovadoras desenvolvidas com apoio de redes internacionais (UNIBAVE, 2013). Seu objetivo é apoiar a rede pública de ensino do sul catarinense no desenvolvimento de projetos inovadores, visando a qualidade e a internacionalização da educação, a inserção tecnológica e o desenvolvimento de práticas inclusivas, transdisciplinares e ecoformadoras e que estimulem o desenvolvimento de cidades sustentáveis (UNIBAVE, 2014).

Em sua dinamização, o programa apoia-se nos pressupostos implícitos na missão do Unibave, os quais também norteiam a atuação da RIEC e da RIEC Brasil, são eles: paradigma ecossistêmico, pensamento complexo, transdisciplinaridade e ecoformação. A proposta ampara-se, portanto, em contribuições de Moraes (1996, 2004), Morin (2001, 2007, 2011, 2014), Mallart (2009), Nicolescu (2005, 2014), Pineau (2000, 2014), Pinho, Suanno, Suanno (2015), Santos (2009), Silva (2008), Torre (2009, 2012, 2013), Zwierewicz $(2013,2014,2015)$, entre outros.

Trata-se de uma proposta educativa conectada com as demandas atuais e com as incertezas em relação ao futuro, e sua inserção nas escolas promove transformações que se refletem na resiliência de gestores, docentes, profissionais técnicos e estudantes, que se envolvem em processos de ensino e aprendizagem mais criativos e contextualizados. Entre os resultados, observa-se a revitalização dos espaços escolares, a ampliação da in- 
teração com a comunidade, o fortalecimento do trabalho colaborativo e a difusão dos resultados em eventos e obras que registram as práticas desenvolvidas (UNIBAVE, 2015).

Atualmente, o programa está vinculado ao Núcleo de Inovação Pedagógica NIP que integra a Pró-Reitoria de Ensino de Graduação - PROGRAD do Unibave. Nesse contexto, atende as políticas de ensino da instituição, especialmente as que se remetem à diretriz voltada para o desenvolvimento da criatividade e inovação nos processos de ensino e aprendizagem (UNIBAVE, 2015).

Para sua dinamização, o programa conta com o apoio dos cursos de Licenciatura em Educação Física e Pedagogia, bem como de Agronomia, Enfermagem, Engenharia Ambiental e Sanitária, Engenharia Civil, Medicina Veterinária, Psicologia e Sistemas de Informação. Destaca-se que, a partir da ampliação da participação de redes municipais no programa, ocorre também a incorporação de novos cursos, estimulando a ampliação da interação entre o Ensino Superior do Unibave e a Educação Básica.

A articulação entre o Ensino Superior do Unibave e a Educação Básica e as mudanças no planejamento dos docentes

O projeto piloto do Programa de Formação-Ação em Escolas Criativas foi desenvolvido em 2008, na Escola Barriga Verde - EBV (Orleans - Santa Catarina), uma instituição mantida pela mesma fundação mantenedora do Unibave. Em 2009, o projeto foi trabalhado na Rede Municipal de Gravatal, uma das cidades situadas na região de abrangência do Unibave, atendendo parte dos docentes vinculados à rede municipal e à rede estadual de ensino.

Em 2013, o programa foi aperfeiçoado e inserido na Rede Municipal de Balneário Rincão, dando início a um processo de consolidação dos trabalhos na Educação Básica. Naquele mesmo ano, uma célula do programa foi desenvolvida em Urussanga, como apoio ao Projeto Urussanga Vira Criança. Em 2014, a Rede Municipal de Educação de Grão Pará aderiu ao Programa; em 2016, foi a vez de São Ludgero; neste mesmo ano voltou a vincular-se também a de Gravatal, que protagonizou o desenvolvimento da proposta em municípios do sul catarinense. O Gráfico 1 representa a incorporação das redes municipais e caracteriza a capilarização do programa no sul catarinense. 
Gráfico 1 - Municípios que participam do Programa de Formação-Ação em Escolas Criativas

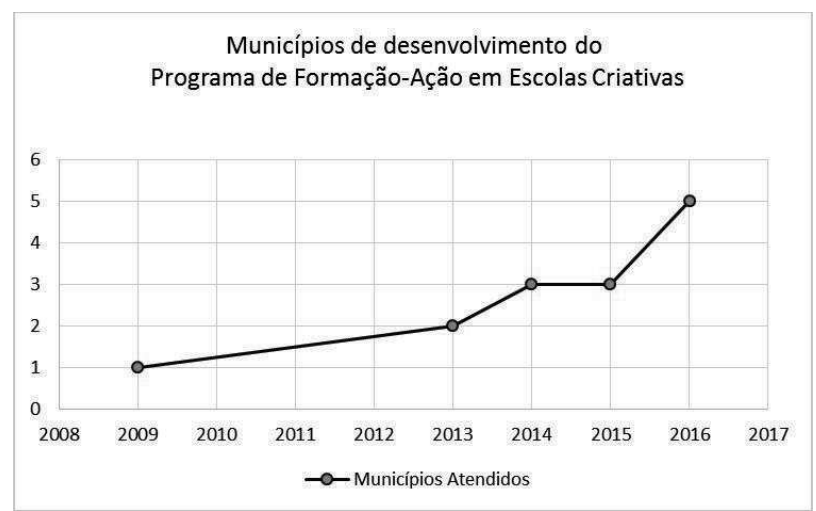

Fonte: Adaptado de Unibave (2016)

Em sete anos, o programa ampliou a interação entre o Ensino Superior e a Educação Básica, viabilizando o desenvolvimento de vários projetos, grande parte deles atendendo os organizadores conceituais dos Projetos Criativos Ecoformadores - PCE. Nesse ínterim, colaborou para ressignificar o planejamento do ensino, provocando a transformação de práticas lineares em propostas traçadas a partir de uma visão mais sistêmica. No Gráfico 2, é apresentada a evolução dos referidos projetos nas redes municipais que participam do programa formativo, incorporando-se também os projetos que estão em desenvolvimento na Escola Barriga Verde - durante este ano de 2016.

Gráfico 2 - Projetos Criativos Ecoformadores desenvolvidos na Educação Básica do sul catarinense

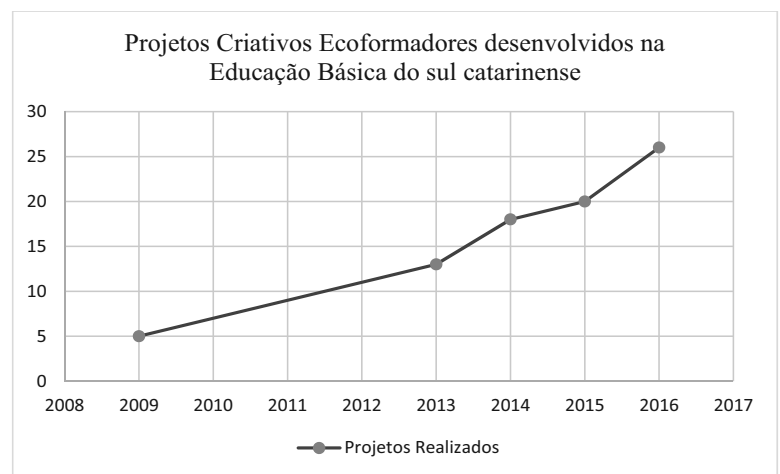

Fonte: Adaptado de Unibave (2016) 
O gráfico indica uma ampliação significativa na elaboração de Projetos Criativos Ecoformadores, que passaram de 5 (cinco) em 2009 para 26 (vinte e seis) em 2016, sendo que há uma previsão de aumento do número ainda para 2016, em função de parte das instituições optarem pela elaboração de projetos semestrais ou trimestrais. Ao apoiar-se na referida metodologia, o programa tem gerado mudanças na forma de conceber o ensino e nas formas de organização das instituições, atendendo a premissa defendida por Morin (2009) de que a reforma da educação depende da reforma do pensamento.

Zwierewicz et al (2015) destacam que as transformações ocorridas têm sido valorizadas por meio de publicações em eventos organizados pelo próprio Unibave ou por parcerias interinstitucionais, tais como: a Jornada das Escolas Criativas (Unibave) o Fórum Internacional de Innovación y Creatividad - INCREA (Universidade de Barcelona - UB e instituições parceiras); o Seminário das Escolas Criativas - RIEC (Universidade Federal de Goiânia - UFG), além de seminários realizados pelas Secretarias de Educação do sul catarinense. De forma complementar, são estimuladas publicações de artigos científicos e livros, como o livro Projetos criativos na prática pedagógica: cantar e encantar a aprendizagem, organizado por Pinho, Suanno e Suanno e lançado em 2015, durante a realização do VII Fórum de Inovação e Criatividade - INCREA e do II Seminário Internacional das Escolas Criativas - RIEC, eventos sediados em Goiânia.

Escolas Criativas: referências de instituições que transcendem, recriam, valorizam e transformam

A metodologia dos Projetos Criativos Ecoformadores - PCE tem sido uma opção adotada no planejamento dos docentes durante o desenvolvimento do Programa de Formação-Ação em Escolas Criativas, em função de sua articulação com a proposta das Escolas Criativas e das transformações que estimula. Além de prever momentos de aprofundamento teórico e de oficinas que auxiliam na seleção de estratégias didáticas e na realização de atividades práticas, o programa contribui para a elaboração dos referidos projetos, por meio das seguintes etapas: a) elaboração da versão preliminar do projeto; b) revisão do projeto pela equipe vinculada ao Núcleo de Inovação Pedagógica do Unibave - NIP; c) envio da versão revisada às instituições de ensino por meio de correio eletrônico; d) visitas da equipe do Núcleo de Inovação Pedagógica do Unibave - NIP às instituições de ensino para a análise das condições de desenvolvimento e aprimoramento do projeto; e) oficinas desenvolvidas pelos cursos de Ensino Superior do Unibave para estimular a promoção de práticas inovadoras; f) seminários locais para a socialização dos resultados do projeto. 
É nesse processo que as instituições de ensino se transformam para transformar a realidade interna e externa. Nesse sentido, o respeito ao ritmo de cada instituição é uma das condições implícitas no trabalho do Núcleo de Inovação Pedagógica - NIP e nos cursos de Ensino Superior do Unibave. Destaca-se que, a partir da inserção no programa, observam-se transformações em todas as Escolas de Ensino Fundamental e nos Centros de Educação Infantil que participam da proposta.

Em função das especificidades que apresentam, foram selecionadas para este estudo seis instituições vinculadas às redes municipais e uma fundacional, as quais têm participado do programa e se tornado referência em função de sua capacidade transformadora, são elas:

- Escola Municipal de Ensino Fundamental Professora Amélia de Souza Silva (Balneário Rincão);

- Centro de Educação Infantil Peixinho Dourado (Balneário Rincão);

- Centro de Educação Infantil Aiurê (Grão Pará);

- Escola de Educação Básica David Silete (Gravatal);

- Centro de Educação Infantil Divina Providência (São Ludgero);

- Centro Educacional Profissional Lydio de Brida (Urussanga);

- Escola Barriga Verde - EBV (Fundação Educacional Barriga Verde - FEBAVE - Orleans).

A seleção se deve à consolidação de uma identidade que vem caracterizando as seis instituições, que é perceptível no trabalho colaborativo, nas transformações geradas interna e externamente e no desenvolvimento de um ensino transdisciplinar e ecoformador, vinculado ao desenvolvimento de cidades sustentáveis. A análise dos Projetos Criativos Ecoformadores - PCE neste estudo, contudo, envolveu três das instituições, em função do período de participação no Programa de Formação-Ação que possibilita avaliar as transformações longitudinalmente, são elas: Escola Municipal de Ensino Fundamental Professora Amélia de Souza Silva, Centro de Educação Infantil Peixinho Dourado e Centro de Educação Infantil Aiurê.

\section{Escola Municipal de Ensino Fundamental Professora Amélia de Souza Silva}

A Escola Municipal de Ensino Fundamental Professora Amélia de Souza Silva integra a Rede Municipal de Educação de Balneário Rincão e atende os anos iniciais do Ensino Fundamental, situando-se como uma das escolas de referência em função do comprome- 
timento dos profissionais que nela atuam com as transformações da realidade interna e da extensão das mudanças no contexto externo, com o intuito de atender demandas sociais, ambientais, econômicas, culturais e políticas da comunidade e do município.

Durante sua participação no Programa de Formação-Ação em Escolas Criativas, desde o ano de 2013, a escola desenvolveu vários Projetos Criativos Ecoformadores - PCE. Tendo como premissa que, ao aprofundar os conhecimentos em relação à história e às características do munícipio, situando cada estudante nesse contexto, a instituição poderia colaborar para a consolidação de uma identidade e o sentimento de pertencimento à comunidade, que pode ser transformada por meio de intervenções fomentadas no entorno escolar (EMEF PROFESSORA AMÉLIA DE SOUZA SILVA, 2016), a instituição tem feito a diferença no seu contexto de inserção.

A apresentação dos Projetos Criativos Ecoformadores - PCE e de seus resultados nos seminários locais de socialização indicam que, entre as transformações geradas pela escola no decorrer dos últimos três anos, destacam-se: a criação da proposta do Lixo de Papel Zero na escola e sua difusão na comunidade; a valorização de uma empresa situada na comunidade que transforma resíduos de papel em embalagens utilizadas em indústrias de cerâmica e de organizações sociais que promovem atividades envolvendo a terceira idade; a revitalização do espaço escolar, com a confecção de horta e composteira, o aproveitamento da água das chuvas e organização de espaços para a leitura; a confecção de material didático a partir de resíduos produzidos pelos estudantes e suas famílias; o trabalho colaborativo, estimulando a criatividade dos docentes e dos estudantes; a ampliação da interação entre escola e comunidade, perceptível no comprometimento das famílias com o desenvolvimento dos estudantes e na participação em atividades promovidas na escola $\mathrm{e}$ fora dela; a adoção, pelos estudantes, de uma parte da orla marítima, com o intuito de preservá-la; o desenvolvimento de um ensino que articula conteúdos curriculares e demandas da realidade, tornando as atividades escolares mais prazerosas e gerando transformações que melhoram a realidade interna e externa; a construção de uma nova escola, atendendo uma das metas do primeiro Projeto Criativo Ecoformador - PCE desenvolvido, momento em que se realizou uma pesquisa sobre a escola dos sonhos dos estudantes e da comunidade (EMEF PROFESSORA AMÉLIA DE SOUZA SILVA, 2016).

Essas ações são parte das conquistas de uma escola que ultrapassa os limites dos conteúdos curriculares para gerar transformações que beneficiam a equipe gestora, os docentes, os profissionais técnicos, os estudantes e a comunidade. São itinerários que despertam o desejo de lutar pelo bem-comum enquanto atendem especificidades inerentes ao desenvolvimento dos estudantes. 


\section{Centro de Educação Infantil Peixinho Dourado}

O Centro de Educação Infantil Peixinho Dourado também integra a Rede $\mathrm{Mu}$ nicipal de Educação de Balneário Rincão e atende com exclusividade crianças da Educação Infantil, situando-se como uma das instituições de referência pelo comprometimento de seus profissionais com transformações no planejamento, que visam articular nos projetos a realidade das crianças e o entorno da instituição, o que oferece maior sentido ao que se trabalha no decorrer do ano letivo.

Desde o ano de 2013, a instituição vem participando do Programa de Formação-Ação em Escolas Criativas e, nesse período, desenvolveu vários Projetos Criativos Ecoformadores - PCE. Tendo como premissa que, ao estimular o autoconhecimento e o conhecimento da realidade passada e presente dos estudantes e dos entornos em que se inserem, podem ser projetadas expectativas em relação ao futuro, com vistas às necessidades e potencialidades detectadas durante o desenvolvimento do projeto (CEI PEIXINHO DOURADO, 2016), a instituição tem transformado sua forma de planejar, valorizando a convivência das crianças com o patrimônio natural e cultural e a consolidação de alternativas para a preservação da vida.

A apresentação dos Projetos Criativos Ecoformadores - PCE e de seus resultados nos seminários locais de socialização indicam transformações geradas pela instituição, dentre as quais se destacam: um aprofundamento dos conhecimentos das crianças em relação ao processo de produção de alimentos, assim como em relação à comunidade/bairro, incluindo suas necessidades e potencialidades, seu contexto geográfico e histórico; a revitalização do espaço interno da instituição com uso de material alternativo; a criação de uma horta escolar; a preservação de um espaço no pátio escolar ocupado por corujas para a postura de ovos, além do estímulo ao cuidado com as referidas aves e seus ninhos; a confecção de material didático a partir de resíduos produzidos pelas crianças e suas famílias; a valorização de situações-problema no desenvolvimento das atividades, estimulando a criatividade individual e coletiva; a adoção de uma visão sistêmica no desenvolvimento das atividades, proporcionando a articulação entre as diferentes dimensões do desenvolvimento infantil; a interação entre os docentes que criam, compartilham e transformam a forma de atuar na instituição (CEI PEIXINHO DOURADO, 2016).

O mapeamento de alguns resultados aponta para o comprometimento de uma equipe com clareza de sua responsabilidade no desenvolvimento das crianças. A preocupação com a dimensão cognitiva, ao aprofundar conhecimentos, com a valorização da dimensão relacional, ao estimular a solução compartilhada e solidária de proble- 
mas, e com o estímulo do desenvolvimento físico-motor, por meio de atividades que envolvem as diferentes áreas do conhecimento, são algumas das iniciativas que têm transformado o Centro de Educação Infantil Peixinho Dourado em uma instituição de referência pela sua capacidade de transcender, recriar, valorizar e transformar.

\section{Centro de Educação Infantil Aiurê}

O Centro de Educação Infantil Aiurê integra a Rede Municipal de Educação de Grão Pará e atende com exclusividade crianças da Educação Infantil, situando-se como uma das instituições de referência por sua capacidade de valorizar a realidade da comunidade, estimulando uma educação a partir da vida e para a vida, perspectiva difundida por Zwierewicz e Torre (2009).

A instituição tem participado do Programa de Formação-Ação em Escolas Criativas desde o ano de 2014 e, nesse período, vem desenvolvendo Projetos Criativos Ecoformadores - PCE que se destacam pelo envolvimento com a realidade local e pelas preocupações com as demandas globais. Tendo como premissas o ensino de qualidade, a inclusão da diversidade e o compromisso com a sustentabilidade, a valorização do docente, entre outras (CEI AIURÊ, 2015a), a instituição tem transformado sua forma de se relacionar com a comunidade e de promover o desenvolvimento integral das crianças atendidas.

A apresentação dos Projetos Criativos Ecoformadores - PCE e de seus resultados nos seminários locais de socialização destacam as seguintes mudanças geradas pela instituição: a transformação de um planejamento fragmentado e linear em um planejamento contextualizado, que promove a articulação entre os eixos da Educação Infantil e destes com a realidade local e as demandas globais; a valorização do produtor e da produção agrícola; o conhecimento das soluções locais para os problemas que permeiam a comunidade situada em uma área rural; o diálogo com pessoas de terceira idade, valorizando suas contribuições para o desenvolvimento local; o conhecimento das formas de produção de energia e a definição de ações que colaboram para a preservação do meio ambiente (CEI AIURÊ, 2015b).

Os resultados sugerem uma equipe de gestores e docentes comprometidos com o desenvolvimento infantil, que estimulam uma prática pedagógica respaldada na realidade das crianças e da comunidade e também o reconhecimento de suas necessidades e de seus potenciais para valorizar e transformar seu contexto de inserção. Seu vínculo com a natureza e a valorização de sua gente faz da instituição uma referência no ensino transdisciplinar e ecoformador. 


\section{Considerações finais}

A articulação entre Ensino Superior e Educação Básica amplia possibilidades para uma dinamização teórico-prática e fortalece a indissociabilidade do ensino, da pesquisa e da extensão. Nesse processo, favorece o distanciamento de um padrão de instituição universitária respaldado pela oferta de um ensino centrado na teoria e de um padrão de escola que restringe sua função ao desenvolvimento de atividades reprodutoras, desvinculadas de um processo permanente de reflexão-ação.

O Programa de Formação-Ação em Escolas Criativas tem impulsionado essa articulação, estimulando mudanças no contexto escolar, assim como o retorno à instituição universitária de problemáticas diagnosticadas durante seu desenvolvimento, fomentando, portanto, novas pesquisas e fortalecendo sua atuação para atender demandas sociais, ambientais, econômicas, políticas e culturais locais e globais. É nesse processo de aproximação do ensino à vida que a metodologia dos Projetos Criativos Ecoformadores - PCE contribui para reproblematizar a relação das pessoas com a natureza, valorizando aquilo que Morin (2011) chama de solidariedade planetária.

A implicação das redes municipais de ensino e das instituições escolares nesse programa tem fortalecido a resiliência de profissionais, estudantes e da comunidade externa, contribuindo para dimensionar seus problemas e criar soluções que qualifiquem a realidade. Nessas práticas, protagonizam-se transformações que se estendem para além dos muros das escolas, dando sentido não apenas aos conteúdos curriculares que são trabalhados a partir da realidade, mas também à universidade, que se transforma para transformar seu entorno.

Espera-se que esta sistematização contribua para valorizar a interação entre o Ensino Superior e a Educação Básica e colabore para que as escolas tenham clareza de que a dinamização dos processos de ensino e aprendizagem implica em concepções pedagógicas que valorizam paradigmas educacionais diferenciados. Nesse sentido, destaca-se o reconhecimento a todas as instituições que têm participado do Programa de Formação-Ação em Escolas Criativas, especialmente por suas capacidades de desafiarem a si mesmas e se oportunizarem o direito de transcender, recriar, valorizar e transformar.

\section{Referências}

CEI AIURÊ. Plano Escolar de Educação - 2015 / 2025. Grão Pará: Cei Aiurê, 2015a.

Uma viagem pela produção da energia: conhecendo o passado e compreendendo o presente. Grão Pará: Cei Aiurê, 2015b. 
CEI PEIXINHO DOURADO. Quem conta um conto abre a cabeça para os sonhos. Balneário Rincão: Cei Peixinho Dourado, 2016.

EMEF PROFESSORA AMÉLIA DE SOUZA SILVA. Comunidade do bem: educar é emancipar o existir humano. Balneário Rincão: EMEF Professora Amélia de Souza Silva, 2016.

FLACH, C. R. de C. BEHRENS, M. A. Paradigmas educacionais e sua influência na prática Pedagógica. In: Congresso Nacional de Educação - EDUCERE, 8, Curitiba. Anais... Curitiba: PUC, 2008, p. 10118- 10129. Disponível em:<http://www.pucpr.br/eventos/ educere/educere2008/anais/pdf/541_365.pdf >. Acesso em 16 de setembro de 2013.

GONZÁLEZ VELASCO, J. M. Religaje Educativo: Espacio- tiempo. La Paz: UMSA, 2015.

LAVILLE, C.; DIONNE, J. A construção do saber: manual de metodologia da pesquisa em Ciências Humanas. Porto Alegre: Artmed, 1999.

MARCONI, M. A; LAKATOS, E. M. Fundamentos de metodologia científica. 6. ed. São Paulo: Atlas, 2006.

MALLART, J. Ecoformação para a escola do século XXI. In: ZWIEREWICZ, M.; TORRE, S. Uma escola para o século XXI: Escolas Criativas e resiliência na educação. Florianópolis: Insular, 2009. p. 29-42.

MENEZES, I. R.; CRUZ, A. R. S. Método de Projeto $x$ Projeto de Trabalho: entre novas e velhas ideias. Sitientibus, Feira de Santana. n. 36. p. 109-125.jan./jun. 2007.

MORAES, M. C. Além da aprendizagem: um paradigma para a vida. In: MORAES, Maria Cândida; TORRE, Saturnino de la (Org.). Sentipensar: fundamentos e estratégias para reencantar a educação. Petrópolis: Vozes, 2004. p. 19-25.

O paradigma educacional emergente: implicações na formação do professor e nas práticas pedagógicas. Em Aberto, Brasília, a. 16, n. 70, abr-jun, 1996.

MORIN, E. A cabeça bem-feita: repensar a reforma, reformar o pensamento. 16. ed. Tradução de Elá Jacobina. Rio de Janeiro: Bertrand Brasil, 2009.

Enseigner à vivre: manifeste pour changer l'éducation. Pars: Actes Sud, 2014. Introdução ao pensamento complexo. 3. ed. Porto Alegre: Sulina, 2007. 
La vía: para el futuro de la humanidad. Barcelona: Paidós, 2011.

Os sete saberes necessários à educação do futuro. 3. ed. São Paulo: Cortez; Brasília: UNESCO, 2001.

MORIN, E.; CIURANA, E.-R.; MOTTA, R. D. Educar na era planetária: o pensamento complexo como método de aprendizagem pelo erro e incerteza humana. Tradução de Sandra Trabucco Valenzuela. 3. ed. São Paulo: Cortez. Brasília: UNESCO, 2009.

NASCIMENTO, R. N. A. A complexidade como matriz de uma nova ecologia cognitiva. 284 p. Tese de Doutorado em Educação. Universidade Federal da Paraíba - UFPB. João Pessoa: Universidade Federal da Paraíba - UFPB , 2007.

NICOLESCU, B. O Manifesto da Transdisciplinaridade. Tradução de Lucia Pereira de Souza. 3. ed. São Paulo: TRIOM, 2005.

Transdisciplinariedad: passado, presente y futuro. In: MARTINEZ, Ana Cecilia; GALVANI, Pascal (Org.). Transdisciplinariedad y formación universitaria: teorías y prácticas emergentes. Puerto Vallarta: CEUArkos, 2014. p. 45-90.

A evolução transdisciplinar da universidade: condição para o desenvolvimentosustentável.In: Congresso International A Responsabilidade da Universidade para com a Sociedade, 1997. Anais... Bangkok: International Association of Universities, Chulalongkorn University, 1997. Disponível em: <http://www.moodle.fmb.unesp.br/ $\mathrm{mod} /$ resource/view.php?id=60>. Acesso em: 27 jun. 2012.

PINEAU G. Temporalités en formation, vers de nouveaux synchroniseurs. Paris: Anthropos, 2000.

Las reflexiones sobre las prácticas: el corazón de la vuelta reflexiva. In: MARTINEZ, Ana Cecilia; GALVANI, Pascal (Org.). Transdisciplinariedad y formación universitaria: teorías y prácticas emergentes. Puerto Vallarta: CEUArkos, 2014. p. 91-114.

PINHO, M. J; SUANNO, M. V. R.; SUANNO, J. H. (Org.). Projetos criativos na prática pedagógica: cantar e encantar a aprendizagem. Goiânia: Espaço acadêmico, 2015.

RICHARDSON, R. J. Pesquisa social: métodos e técnicas. 3. ed. São Paulo: Atlas, 1999.

SANTOS, A. Complexidade e transdisciplinaridade em educação: cinco princípios para 
resgatar o elo perdido. In: SANTOS, Akiko; SOMMERMAN, Américo. Complexidade e transdisciplinaridade: em busca da totalidade perdida. Porto Alegre: Sulina, 2009. p. 15-38.

SILVA, A. T. R. Ecoformação: reflexões para uma pedagogia ambiental, a partir de Rousseau, Morin e Pineau. Desenvolvimento e Meio Ambiente, Curitiba, UFPR, n. 18, p. 95-104, jul./dez. 2008

TORRE, S. Escolas Criativas: escolas que aprendem, criam e inovam. In: ZWIEREWICZ, Marlene; TORRE, Saturnino de la (Org.). Uma escola para o século XXI: escolas criativas e resiliência na educação. Florianópolis: Insular, 2009. p. 55-70.

Movimento de Escolas Criativas: fazendo parte da história de formação e transformação. In: ZWIEREWICZ, Marlene (Org.). Criatividade e inovação no Ensino Superior: experiências latino-americanas em foco. Blumenau: Nova Letra, 2013. p. $139-162$.

TORRE, Saturnino de la; ZWIEREWICZ, Marlene. Projetos Criativos Ecoformadores. In: ZWIEREWICZ, Marlene; TORRE, Saturnino de la (Org.). Uma escola para o século XXI: escolas criativas e resiliência na educação. Florianópolis: Insular, 2009. p. $153-176$.

UNIBAVE. Programa de Formação-Ação em Escolas Criativas. Orleans: Unibave, 2016.

ZWIEREWICZ, M. Apresentação. In: ZWIEREWICZ, Marlene (Org.). Criatividade e inovação no Ensino Superior: experiências latino-americanas em foco. Blumenau: Nova Letra, 2013. p. 9-16.

Metodologia do Ensino Superior. Florianópolis: Senac, 2015.

Seminário de pesquisa e intervenção. Florianópolis: IFSC, 2014.

ZWIEREWICZ, M. et al. Implicações das Escolas Criativas e dos Projetos Criativos Ecoformadores no programa de formação-ação de docentes da Educação Básica e do Ensino Superior. In: Senpex, VI, 2015, Orleans. Ciência e tecnologia para a promoção da educação e da vida. Orleans: Unibave, 2015. p. 591-596.

Recebido em: 18 abril 2016.

Aceito em: 28 abril 2016. 